\title{
Evaluation of the Adoption of a Connected Device to Monitor and improve patient's adherence and persistence to therapy using real-world data
}

Lara Kelly ${ }^{*}$, MSc (BiomedEng), BA, BAI (MechEng); Akshay Dattatray Zalkikar ${ }^{*}$, BE, MSc; John G Armstrong*, FRCPI, MD, DABR, FFRRCSI

HealthBeacon, Dublin, Ireland

*all authors contributed equally

\section{Corresponding Author:}

Lara Kelly, MSc (BiomedEng), BA, BAI (MechEng)

HealthBeacon

Unit 20 Naas Road Business Park

Dublin

Ireland

Phone: +35 314508480

Email: 1ara.kelly@healthbeacon.com

\begin{abstract}
Background: The HealthBeaconTM is a smart sharps bin for patients who self-inject medications at home. It is digitally connected and programmed with a patient's medication schedule and uses customized reminders to help them start and stay on track with their medication. The HealthBeacon device was launched in May 2015; since then, it has been used by 8000+ patients and has tracked 250,000+ injections across 11 markets. The HealthBeacon is designed to be passive. The patient is not asked to do anything; the device captures the act of disposal which is a highly accurate method for measuring drug adherence. Several studies on the adoption of self-tracking devices have found that the percentages of people who stopped using their device within relative short-term follow up periods may vary between $33-75 \%$. A behavioral analysis was completed to determine if the patient-centric design of HealthBeacon technology can overcome barriers to patient adoption and improve persistence to therapy.

Objective: The objective was to evaluate the adoption of a connected device to monitor and improve patient adherence and persistence to therapy.

Methods: For the purpose of the study the patients were classified into two categories. 1) If all conditions outlined below were met, the patient "adopted" the technology: A) Patient consented to support program; B) HealthBeacon was delivered and established in the home; C) Patient utilized the technology correctly; D) Technology successfully tracked injections and communicated with HealthBeacon platform; E) Patient remains on HealthBeacon achieving high persistence to medication or continued until treatment completion. 2) If any of the following circumstances arose, the patient was considered as "rejected" as they failed to adopt the technology: A) Upon introduction to HealthBeacon the patient requested a regular sharps bin; B) Patient never disposed an injection into the HealthBeacon; C) Patient has not interacted with the device for 90+ days; D) Patient accepted the HealthBeacon initially but returned it for reasons other than their treatment ending
\end{abstract}

Results: Data were measured over a 24-month period from May 2017 to May 2019 for the 756 patients were involved in the study; $584(77 \%)$ of the patients adopted the technology and $172(23 \%)$ rejected it. Of the patients that adopted, $478(82 \%)$ continue to utilize the technology and $106(18 \%)$ are no longer active. The reason for stopping was associated with their treatment ending rather than an adoption issue. Of the 172 patients $(23 \%)$ rejected the technology, $26(15 \%)$ requested a standard sharps bin after receiving the introduction; $45(26 \%)$ accepted the HealthBeacon but never disposed an injection into it; $86(50 \%)$ used the HealthBeacon initially but had not interacted with it for 90+ days; $2(1 \%)$ rejected it due to a technical issue; and $13(8 \%)$ accepted it initially but reported that they prefer to manage adherence on their own.

Conclusions: With almost $80 \%$ of patients adopting the technology, and $82 \%$ of the adopters persisting, this study demonstrates that patient-centered design that deploys passive adherence monitoring can overcome barriers to adoption of technology.

(iproc 2019;5(1):e15227) doi: $\underline{10.2196 / 15227}$ 


\section{KEYWORDS}

adherence; persistence; connected health; digital tools; adoption; patient-centric design

Edited by J Brown; this is a non-peer-reviewed article. Submitted 27.06.19; accepted 13.08.19; published 02.10.19.

Please cite as:

Kelly L, Zalkikar AD, Armstrong JG

Evaluation of the Adoption of a Connected Device to Monitor and improve patient's adherence and persistence to therapy using real-world data

iproc 2019;5(1):e15227

URL: http://www.iproc.org/2019/1/e15227/

doi: $\underline{10.2196 / 15227}$

PMID:

CLara Kelly, Akshay Dattatray Zalkikar, Professor John. G Armstrong. Originally published in Iproceedings (http://www.iproc.org), 02.10.2019 This is an open-access article distributed under the terms of the Creative Commons Attribution License (https://creativecommons.org/licenses/by/4.0/), which permits unrestricted use, distribution, and reproduction in any medium, provided the original work, first published in Iproceedings, is properly cited. The complete bibliographic information, a link to the original publication on http://www.iproc.org/, as well as this copyright and license information must be included. 